chasing and services programs to reduce their operational costs.

With the Ohio Third Frontier, OPSC, PolymerOhio, and investments in other organizations such as the Ohio Bioproducts Innovation Center, Ohio Nano-Network, the National Composite Center, and the Center for Multifunctional Polymers, Nano-Materials and Devices, the state of Ohio is a growing hub of polymer activity. Companies and research institutions are engaged at all points along the supply chain in areas ranging from aerospace to flexible displays.

The polymer industry in Ohio employs approximately 130,000 people at 2440 establishments. It has generated nearly $\$ 50$ billion in economic activity and more than $\$ 1.3$ billion in exports annually in recent years. For more information on Ohio's investments in the polymer community, visit www. PolymerOhio.org.

\section{Kendra Redmond}

Science Europe to strengthen collaboration among national research organizations
L ast fall, Europe's national research organizations announced the founding of Science Europe, an organization that brings together 50 organizations from across Europe. Based in Brussels, Science Europe will promote the collective interests of its member organizations, and streamline the coordination of policies and activities. Its creation will accelerate progress on implementing the actions set out in the road map for the realization of the European Research Area developed by the European Heads of Research Councils (EUROHORCs) and the European Science Foundation in 2009. Its location in Brussels will enable Science Europe to work in effective partnership with the European Commission and other European organizations with similar aims.

In addition to coordinating policy work among its members, in 2012, Science Europe will establish six scientific committees that will be made up of leading European researchers to ensure a direct voice for the scientific community in the organization's strategic outlook, policies, and priorities.

As Science Europe's first president, Assembly-elected Paul Boyle of the
Research Councils UK said, "Science Europe will provide a strong single voice for research funding and performing organizations in Europe; it is essential for us to work together to support research to address the global challenges we face today."

Preparations for the establishment of Science Europe have been in development for two years, and a Pilot Board, with a small Pilot Office in Brussels, has been operating since February 2011 to prepare for its establishment and enable a Secretariat to be operational quickly. The Pilot Office has also been working closely with the European Science Foundation to ensure coherence and avoid duplication of activity.

German Research Foundation to fund three DNP-NMR devices for materials science

W

ith support from the Deutsche Forschungsgemeinschaft (DFG, German Research Foundation) three German universities are to obtain innovative dynamic nuclear polarization-nuclear magnetic resonance (DNP-NMR) equipment for use in materials science and the life sciences. As part of an ongoing major instrumentation initiative, a sum of almost $€ 5$ million is available to provide this technology at the Universities of Darmstadt, Düsseldorf, and Frankfurt.

The key feature of DNP-NMR tech- nology is the combination of solidstate NMR spectroscopy with intensive high-frequency irradiation of the samples during the measurement. This technique increases the sensitivity of the NMR measurement by approximately two orders of magnitude and so allows completely new categories of samples to be investigated, according to the DFG. In contrast to other approaches to more sensitive NMR measurements, the new method now being funded enables continuous DNP amplification for the first time, and thereby affords wider appli- cation in a range of different scientific fields, said the DFG. This means that the DNP-NMR technique may facilitate a better understanding of the interactions taking place on the molecular level.

In materials science, for example, this instrumentation can be used for studying composite materials, glasses, or inhomogeneous polymers.

The equipment to be funded by the DFG is intended to contribute to exploiting and evaluating the potential of the DNP-NMR technology. At all funded sites, measurement time will be available for external users, for which they will be expected to pay a share of the running costs. 